\title{
Deposition of inhaled particles in the mouth and throat of asthmatic subjects
}

\author{
K. Svartengren*, P-Å. Lindestad**, M. Svartengren ${ }^{+\$}$, \\ G. Bylin*, K. Philipson $\$$, P. Camner
}

Deposition of inhaled particles in the mouth and throat of asthmatic subjects. $K$. Svartengren, P-A Lindestad, M. Svartengren, G. Bylin, K. Philipson, P. Camner. CERS Journals Ltd 1994.

ABSTRACT: We previously studied the deposition of inhaled particles in the mouth and throat of asthmatic patients, and found large, reproducible differences among subjects. In the present study, we examined whether anatomical and/or functional differences in the pharynx and larynx could underlie this interindividual variation.

Deposition in the mouth and throat, and in the lung was estimated in 16 asthmatic subjects after inhalation of $3.6 \mu \mathrm{m}$ (aerodynamic diameter) monodisperse Teflon particles labelled with ${ }^{111} \mathrm{In}$. The particles were inhaled at a flow rate of 0.5 $l \cdot \mathrm{s}^{-1}$ with maximally deep breaths. Radioactivity was measured by external scanning over head and neck, lungs and stomach, immediately after the inhalation. Radioactivity in the lungs was also measured $24 \mathrm{~h}$ later. A measure of the total amount of particles deposited in the mouth and throat was obtained from the added activities in mouthwash, head and neck, and stomach, immediately after the inhalation of the test particles. Pharynx and larynx function was examined by fibreoptic laryngoscopy performed during a corresponding inhalation procedure.

Deposition in the mouth and throat varied widely among the subjects, ranging 9-76\% (median 12\%). We found two subpopulations, 13 subjects in the range 9-34\%, and 3 subjects with $>\mathbf{7 0 \%}$ deposition. Deviations in pharyngeal configuration during inhalation were significantly related to high mouth and throat deposition, whereas functional differences in the larynx were not.

Our study shows that mouth and throat deposition may be extremely high in some asthmatics, and that pharyngeal configuration affects deposition of particles in the mouth and throat.

Eur Respir J., 1994, 7, 1467-1473.
Depts of *Respiratory and Allergic Diseases, **Logopedics and Phoniatrics, and ${ }^{\dagger}$ Occupational Medicine, Karolinska Institute, Huddinge University Hospital, Huddinge, Sweden. ${ }^{\$}$ Division of Inhalation Toxicology, Institute of Environmental Medicine, Karolinska Institute, Stockholm, Sweden.

Correspondence: K. Svartengren Dept of Respiratory and Allergic Diseases M53, Huddinge University Hospital S-141 86 Huddinge Sweden

Keywords: Bronchial asthma laryngoscopy

particle deposition

upper airways

Received: December 311993

Accepted after revision April 161994

Supported by grants from the Swedish Heart Lung Foundation, the National Swedish Environmental Protection Board, and the Herman Krefting Allergy and Asthma Research Fund.
Therapeutic aerosols have gained a prominent role in treating bronchial asthma. Studies of mouth and throat deposition in healthy subjects [1-3], as well as in asthmatics [4], have shown wide interindividual variations, even during well standardized inhalation procedures. Deposition of inhaled $3.6 \mu \mathrm{m}$ particles in the mouth and throat varied between $7-66 \%$ in asthmatics, with high deposition $(>30 \%)$ in a quarter of the population, and low deposition $(<30 \%)$ in the remaining three quarters [4]. These variations were well reproducible. The correlation factor between two inhalations in 20 sub- jects was 0.84 , indicating individual factors. For pa-tients on long-term treatment with therapeutic aerosols, it is of importance whether 10 or $70 \%$ deposit in the mouth and throat, partly because a reduced dose of the therapeutic aerosol will reach the lung, and partly because an increased deposition in mouth and throat may cause adverse effects.

The aim of the present study was to investigate the reasons behind these differences in mouth and throat deposition. We separated patients with high deposition from those with low deposition, and examined whether anatomical and/or functional differences in pharynx and larynx would be associated with mouth and throat, and with lung deposition. We also measured lung function for evaluation of a possible correlation with alveolar deposition, i.e. the percentage retention of particles in the lungs after $24 \mathrm{~h}\left(\operatorname{Ret}_{24}\right)$. Deposition in the mouth and throat, and in the lung was estimated in 16 asthmatics after inhalation of $3.6 \mu \mathrm{m}$ diameter radiolabelled particles, and pharynx and larynx function was assessed by laryngoscopy. This particle size is within the range of most therapeutic aerosols.

\section{Methods}

\section{Design}

Sixteen subjects with asthma inhaled monodisperse Teflon particles (3.6 $\mu \mathrm{m}$ aerodynamic diameter) labelled with ${ }^{111} \mathrm{In}$. Regional deposition was estimated by 
adjusting the gamma counts recorded in the measurements of head and neck, lungs, and stomach to absolute values, using factors for self-absorption obtained from measurements in a phantom and by adding the activities in mouthwash. The total inhaled activity was obtained by adding the activities from an exhalation filter. All subjects rinsed their mouths with water immediately before profile scanning and the radioactivity in the water was measured separately after the scanning was carried out. The amount of particles deposited in mouth and throat was estimated from the total amount of extrathoracic deposited particles, i.e. by adding the activities measured in mouthwash, head and neck, and stomach after the inhalation of the test particles. Radioactivity was also measured over the lungs $24 \mathrm{~h}$ later in 15 subjects. Lung function tests were performed on the same day as the exposure to the Teflon particles.

All subjects underwent a laryngoscopic examination a week later. The examination was performed during inhalation using the same standardized procedure as was used for the deposition measurements. The findings in pharynx and larynx were video-recorded and assessed in a blinded fashion without knowledge of the deposition results and vice versa. Mouth and throat deposition, as well as lung retention after $24 \mathrm{~h}\left(\operatorname{Ret}_{24}\right)$, were correlated to qualitative characteristics found in pharynx and larynx.

\section{Subjects}

Sixteen subjects with mild to moderately severe asthma (6 males and 10 females) volunteered for the study, which was approved by the Ethics Committee on $\mathrm{Hu}-$ man Research of the Karolinska Institute. Personal and lung function data, as well as duration of asthma, are given in table 1. Three subjects (Nos. 7, 12 and 13) showed low values of forced expiratory volume in one second $\left(\mathrm{FEV}_{1}\right)$. These values were temporarily low at the time of the investigation, but on other occasions were documented as normal. All subjects but one were nonsmokers (9 lifetime nonsmokers, 6 ex-smokers) and all had recurrent attacks of reversible dyspnoea with wheezing. Thirteen had a history of allergy. All used beta $_{2}$-agonists (inhaled and/or orally taken), eleven inhaled steroids daily, three used oral steroids, and five oral theophylline. Adverse effects of inhaled steroids, such as oral candidiasis and hoarseness, were reported to occur frequently in four subjects and occasionally in two subjects. The remaining subjects did not report any side-effects.

\section{Lung function tests}

Forced vital capacity (FVC), $\mathrm{FEV}_{1}$, flow-volume loops (forced expiratory flow at $75-85 \%$ of $\mathrm{FVC}\left(\mathrm{FEF}_{75-85 \%}\right)$ ), and single-breath oxygen $\left(\mathrm{SBO}_{2}\right)$-test were measured using a Lung Function Laboratory 2100 (SensorMedics, USA). The manoeuvre of the $\mathrm{SBO}_{2}$-test was a complete exhalation (to residual volume (RV)) followed by a full inhalation (to total lung capacity (TLC)) of $100 \%$ oxygen and, finally, a complete exhalation, with a flow rate of $0.3-0.6 l \cdot \mathrm{s}^{-1}$. During the exhalation, the $\mathrm{N}_{2}$ concentration in the exhaled air was continuously measured. The slope of phase III, given as $\mathrm{N}_{2}$-delta, was calculated as the mean of at least two tests. The subjects wore a noseclip and were in a sitting position.

Table 1. - Personal and lung function data

\begin{tabular}{|c|c|c|c|c|c|c|c|c|c|}
\hline \multirow{2}{*}{$\begin{array}{l}\text { Subject } \\
\text { No. }\end{array}$} & \multirow[t]{2}{*}{ Sex } & \multirow{2}{*}{$\begin{array}{l}\text { Age } \\
\text { yrs }\end{array}$} & \multirow{2}{*}{$\begin{array}{c}\text { Height } \\
\mathrm{cm}\end{array}$} & \multirow{2}{*}{$\begin{array}{c}\text { Weight } \\
\text { kg }\end{array}$} & \multicolumn{2}{|c|}{$\mathrm{FEV}_{1}$} & \multicolumn{2}{|c|}{ FVC } & \multirow{2}{*}{$\begin{array}{c}\text { Duration } \\
\text { of asthma } \\
\text { yrs }\end{array}$} \\
\hline & & & & & $l$ & $\%$ pred $*$ & $l$ & $\%$ pred* & \\
\hline 1 & $\mathrm{~F}$ & 49 & 148 & 55 & 2.15 & 89 & 2.75 & 96 & 6 \\
\hline 2 & $\mathrm{M}$ & 65 & 178 & 75 & 2.51 & 77 & 4.53 & 108 & 65 \\
\hline 3 & M & 37 & 194 & 92 & 5.02 & 107 & 6.68 & 115 & 26 \\
\hline 4 & $\mathrm{~F}$ & 28 & 180 & 68 & 3.68 & 96 & 4.22 & 96 & 14 \\
\hline 5 & $\mathrm{M}$ & 28 & 170 & 60 & 3.62 & 90 & 4.87 & 102 & 28 \\
\hline 6 & $\mathrm{~F}$ & 32 & 173 & 82 & 3.13 & 92 & 4.04 & 103 & 17 \\
\hline 7 & $\mathrm{~F}$ & 47 & 164 & 62 & 1.13 & 41 & 2.29 & 71 & 47 \\
\hline 8 & $\mathrm{~F}$ & 47 & 162 & 60 & 2.42 & 91 & 3.14 & 102 & 3 \\
\hline 9 & $\mathrm{~F}$ & 49 & 168 & 74 & 1.68 & 60 & 2.58 & 79 & 48 \\
\hline 10 & $\mathrm{~F}$ & 41 & 163 & 85 & 2.48 & 90 & 3.02 & 94 & 16 \\
\hline 11 & $\mathrm{M}$ & 39 & 176 & 67 & 3.02 & 77 & 4.80 & 101 & 33 \\
\hline 12 & M & 30 & 183 & 67 & 1.97 & 44 & 4.50 & 83 & 14 \\
\hline 13 & M & 38 & 173 & 79 & 2.08 & 55 & 3.45 & 75 & 38 \\
\hline 14 & $\mathrm{~F}$ & 25 & 173 & 107 & 3.96 & 110 & 4.95 & 120 & 6 \\
\hline 15 & $\mathrm{~F}$ & 36 & 173 & 70 & 3.26 & 98 & 4.23 & 111 & 36 \\
\hline 16 & $\mathrm{~F}$ & 23 & 162 & 62 & 3.53 & 110 & 4.03 & 110 & 9 \\
\hline Mean & & 38 & 171 & 73 & 2.85 & 83 & 4.00 & 98 & 25 \\
\hline $\mathrm{SD}$ & & 11 & 10 & 14 & 0.98 & 22 & 1.11 & 14 & 18 \\
\hline
\end{tabular}

*: predicted values according to QUANJER [5]. M: male; $\mathrm{F}$ : female; $\mathrm{FEV}_{1}$ : forced expiratory volume in one second; \% pred: percentage of predicted value; FVC: forced vital capacity. 
Airway resistance (Raw), and thoracic gas volume (TGV) were measured using a panting technique within a whole-body plethysmograph (Transmural Body Box 2800, SensorMedics, USA). All lung function parameters were determined according to the criteria proposed by QUANJER [5].

\section{Deposition measurements}

Production and inhalation of the test particles. The Teflon particles were produced and labelled with ${ }^{111} \mathrm{In}$ (half-life $68 \mathrm{~h}$ ) by a spinning disc technique $[6,7]$. The mean geometric particle diameter was $2.5 \mu \mathrm{m}$, with a coefficient of variation of $<10 \%$, estimated by measurements in a light microscope (Visopan projection microscope, Reichert, Austria). From the density of the Teflon particles, $2.13 \mathrm{~g} \cdot \mathrm{cm}^{-3}$ [7], the mean aero-dynamic diameter was calculated to be $3.6 \mu \mathrm{m}$. The particles were made wet and well dispersed by the addition of $0.2 \%$ tergitol TMN (trimethylnonylether of polyethyleneglycol). The excess of tergitol and loosely bound ${ }^{111}$ In was removed by washing the particles in water at $37^{\circ} \mathrm{C}$. The leakage of ${ }^{111} \mathrm{In}$ of the washed particles was $<1 \%$ per day. Before the particles were aerosolized, they were suspended in water $\left(0.7 \mathrm{mg}\right.$ particles $\left.\cdot \mathrm{ml}^{-1}\right)$ and 0.2 $\mathrm{ml}$ of the suspension was sprayed up 2-3 times into a $25 l$ glass bulb with a jet spray (Beckman Atomizer) [6]. We ascertained that there was no visible mist before starting the inhalation. If necessary, dry air was released into the bulb. The subjects inhaled the particles (approximately $10 \mu \mathrm{g}$ ) with 8-10 maximally deep inhalations, at a flow rate of $0.5 l \cdot \mathrm{s}^{-1}$ during 3-5 min, with a pause of 1-2 $\mathrm{s}$ between inhalation and exhalation in order to allow all particles to deposit. The flow rate, which was measured with a pneumotachograph positioned between the bulb and the mouthpiece, was recorded. The subjects could inhale at a fairly constant rate throughout the inspiration by looking at the recorder needle. All subjects were trained to inhale in this manner before they inhaled the test particles. The exhalations during exposure were performed through a low-resistance filter (Inspiron) in order to collect exhaled particles. The total amount ex-haled was less than $2 \%$ of the inhaled radioactivity. The radioactivity deposited in the lungs was about $70 \mathrm{kBq}$.

Measurements of radioactivity. Radioactivity was measured using two $13 \times 5 \mathrm{~cm}$ NaI crystals fitted with collimators [6]. Profile scanning over head and neck, lungs, and stomach was performed twice immediately after inhalation, and repeated $24 \mathrm{~h}$ later over the lungs. The counts from the two detectors were measured and recorded separately. This permitted discrimination between the activities in lungs and stomach, as the activity in the stomach is apparently much lower in the right than in the left detector, due to absorption in the liver. Radioactivity in mouthwash and exhalation filters was also measured using the profile scanner. The measured radioactivity in mouthwash was in the order of $1 \%$ of the total inhaled activity.
Phantom measurements. Self-absorption (attenuation) was estimated by introducing a small source of ${ }^{111} \mathrm{In}$ to different parts of the head and throat, the lungs, and the stomach of a phantom (Average man Rando Phantom, Alderson Research Laboratories). It has been demonstrated in earlier work [8] that compared to air, the average self-absorption was 2 for mouth and throat, 2.5 for lungs, and 4 for the stomach. Even rather large changes between these self-absorption factors have only a minor effect on the percentage regional deposition [4].

\section{Laryngoscopic procedure}

Fibreoptic pharyngo- and laryngoscopy was performed by nasal introduction of a flexible laryngoscope (Olympus ENF-P3, $3.5 \mathrm{~mm}$ o.d.). This procedure is currently used in routine ear, nose and throat (ENT) examinations and is well-tolerated by most patients. Topical anaesthesia of one nostril with lidocaine spray (10\% Xylocaine spray, Astra, Sweden) was given prior to examination in all subjects. No anaesthetization of the pharynx or the larynx was needed. The subjects did not suffer from any discomfort during the examination and could carry out inhalations undisturbed.

The behaviour of the upper airway was observed at two levels during inhalation. Pharyngeal shape was studied with the tip of the instrument placed in the upper oropharynx, just below the uvula. Laryngeal shape was focused after the tip of the instrument was moved down to a few millimetres above the tip of the epiglottis. The subjects inhaled several times to obtain recordings of technically high quality. The onset and offset of inhalations were indicated by on-line comments on the videotape by the experimenter, who monitored the airflow and instructed the patients. The examinations were recorded with standard video equipment and analysed off-line by one of the authors (P-A L). There was little, if any, observable variation among inhalations within the subjects. The reliability of the method was evaluated by re-examining five subjects (Nos. 1, 6, 7, 9 and 13) a year later. They all exhibited the same behaviour during inhalation and, accordingly, the classification was consistent with that documented before.

After a first analysis of all examinations it was evident that the shape and function during inhalation could be divided into three categories (A, B or $\mathrm{C}$ ), according to the following criteria:

Pharynx:

A. A wide open space throughout the whole inhalation. B. A moderate narrowing at the tongue-base-epiglottic level, significant tonsil enlargement, or deviant epiglottal shape narrowing the glottal entrance.

C. A marked constriction at the tongue-base-epiglottic level.

Larynx:

A. Wide angle between the vocal folds during the major part of the inhalation time.

B. Wide angle between the vocal folds at onset, then considerable adduction during at least half of the inhalation time. 
C. Wide angle for less than one second, then a marked vocal fold adduction with a small angle between the folds throughout the rest of the inhalation.

\section{Statistical analysis}

The Fisher exact probability test was used for analysing the categories for high and low mouth and throat deposition and qualitative characteristics found in pharynx and larynx. In analysing lung retention versus pharynx and larynx characteristics, the Student's t-test was used. The level of significance was 0.05 .

\section{Results}

Table 2 gives the individual values of regional deposition immediately after the inhalation of the Teflon particles, and the percentage retention of particles in the lungs after $24 \mathrm{~h}\left(\operatorname{Ret}_{24}\right)$. It also gives the categories of the pharynx and larynx of each subject. The percentage depositions in mouth and throat are presented in figure 1. These values, obtained in the first scan, may be regarded as upper limit values, as some activity might have been swallowed during the scanning and could, thus, have been measured twice, i.e. first in the mouth and throat and later in the stomach. A lower limit value can be estimated using the activities measured in the stomach in the first scan and in the mouth

Table 2. - Deposition in the mouth and throat, and lung immediately after inhalation of the particles, lung retention at $24 \mathrm{~h}\left(\mathrm{Ret}_{24}\right)$, and characteristics found in the pharynx and larynx

\begin{tabular}{cccccc}
\hline Sbt & $\begin{array}{c}\text { Mouth and } \\
\text { throat } \\
\text { No. }\end{array}$ & Lung & Ret $_{24}^{*}$ & Pharynx & Larynx \\
\hline 1 & 71 & 29 & 51 & $\mathrm{C}$ & $\mathrm{C}$ \\
2 & 10 & 90 & 68 & $\mathrm{~A}$ & $\mathrm{~A}$ \\
3 & 11 & 89 & 69 & $\mathrm{~B}$ & $\mathrm{~A}$ \\
4 & 9 & 91 & 74 & $\mathrm{~B}$ & $\mathrm{~A}$ \\
5 & 11 & 89 & 69 & $\mathrm{~A}$ & $\mathrm{~A}$ \\
6 & 11 & 89 & 58 & $\mathrm{~A}$ & $\mathrm{~B}$ \\
7 & 34 & 66 & 60 & $\mathrm{~A}$ & $\mathrm{~A}$ \\
8 & 20 & 80 & 63 & $\mathrm{~A}$ & $\mathrm{~B}$ \\
9 & 76 & 24 & 42 & $\mathrm{C}$ & $\mathrm{C}$ \\
10 & 23 & 77 & 57 & $\mathrm{~A}$ & $\mathrm{~A}$ \\
11 & 25 & 75 & 59 & $\mathrm{~A}$ & $\mathrm{~B}$ \\
12 & 9 & 91 & - & $\mathrm{A}$ & $\mathrm{C}$ \\
13 & 71 & 29 & 36 & $\mathrm{~B}$ & $\mathrm{~A}$ \\
14 & 11 & 89 & 54 & $\mathrm{~A}$ & $\mathrm{~A}$ \\
15 & 13 & 87 & 85 & $\mathrm{~A}$ & $\mathrm{~A}$ \\
16 & 11 & 89 & 77 & $\mathrm{~B}$ & $\mathrm{~A}$ \\
\hline deposition & & & & \\
Mean & 26 & 74 & 62 & & \\
SD & 24 & 24 & 13 & & \\
\hline
\end{tabular}

The criteria of category A, B and C are given in the Methods section. +: deposition in percentage of inhaled particles; *: retained particles after $24 \mathrm{~h}$ in percentage of the initial amount of lung deposition.

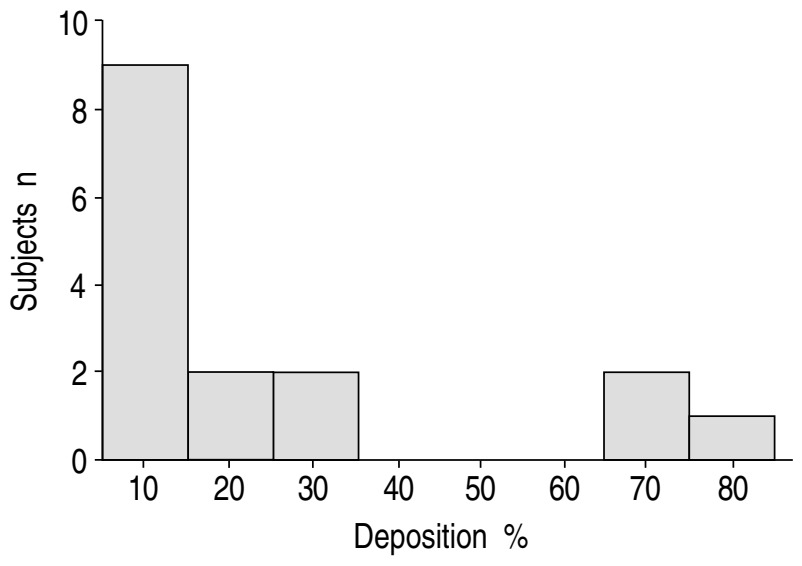

Fig. 1. - Distribution of deposition of $3.6 \mu \mathrm{m}$ inhaled particles in the mouth and throat of 16 asthmatic subjects. The median was $12 \%$.

and throat in the second scan, as the activities which are swallowed between the two scannings are not measured at all. However, the difference between the upper and lower limit values were on average only $1.2 \%$ units, with a maximum difference of only $5 \%$ units. We found wide variations among the patients, ranging $9-76 \%$ (table 2). The mean \pm SD was $26 \pm 24 \%$, and the median was $12 \%$. Two distinct subpopulations were found, 13 patients in the range 9-34\%, and three with $>70 \%$ deposition (fig. 1). Figure 2 demonstrates radioactivity profiles measured by external scanning over mouth and throat, lungs, and stomach immediately after inhalation of the test particles. Two asthmatic subjects are shown, one with (subject No. 9), and one without (subject No. 15), high activity measured over mouth and throat. These profiles show that the maximum mouth and throat activity is anatomically located over pharynx, and not over larynx, i.e. between the tragus of the external ear and the cricoid cartilage of the larynx.

The fibreoptic examination revealed functional as well as anatomical differences both in pharynx and larynx. In table 3 , in accordance with the categories A, B and $\mathrm{C}$ (defined above), mouth and throat deposition is given versus characteristics found in pharynx and larynx. Included in the same table are also the Ret ${ }_{24}$ values versus the above characteristics. Due to the small number of patients in each category (see table 2), the characteristics of pharynx and larynx were divided into two groups, one containing all subjects found to have wide open spaces throughout the whole inhalation (A), and the other combining the remaining subjects found to have some deviation concerning function or shape of their spaces $(\mathrm{B}+\mathrm{C})$. The mouth and throat deposition values above $70 \%$ found in the three subjects were significantly related to $\mathrm{B}+\mathrm{C}$ evaluation of the pharynx tested by the Fisher exact probability one-tailed test for 2 $\times 2$ tables $(\mathrm{p}<0.05)($ table 4$)$. Included in the group with $\mathrm{B}+\mathrm{C}$ evaluation, as shown in table 4 , were also three subjects found to have low mouth and throat deposition values. Table 5 presents the specific deviations found in the pharynx in this group of six subjects. A narrowing of the larynx $(\mathrm{B}+\mathrm{C})$, on the other hand, was not 


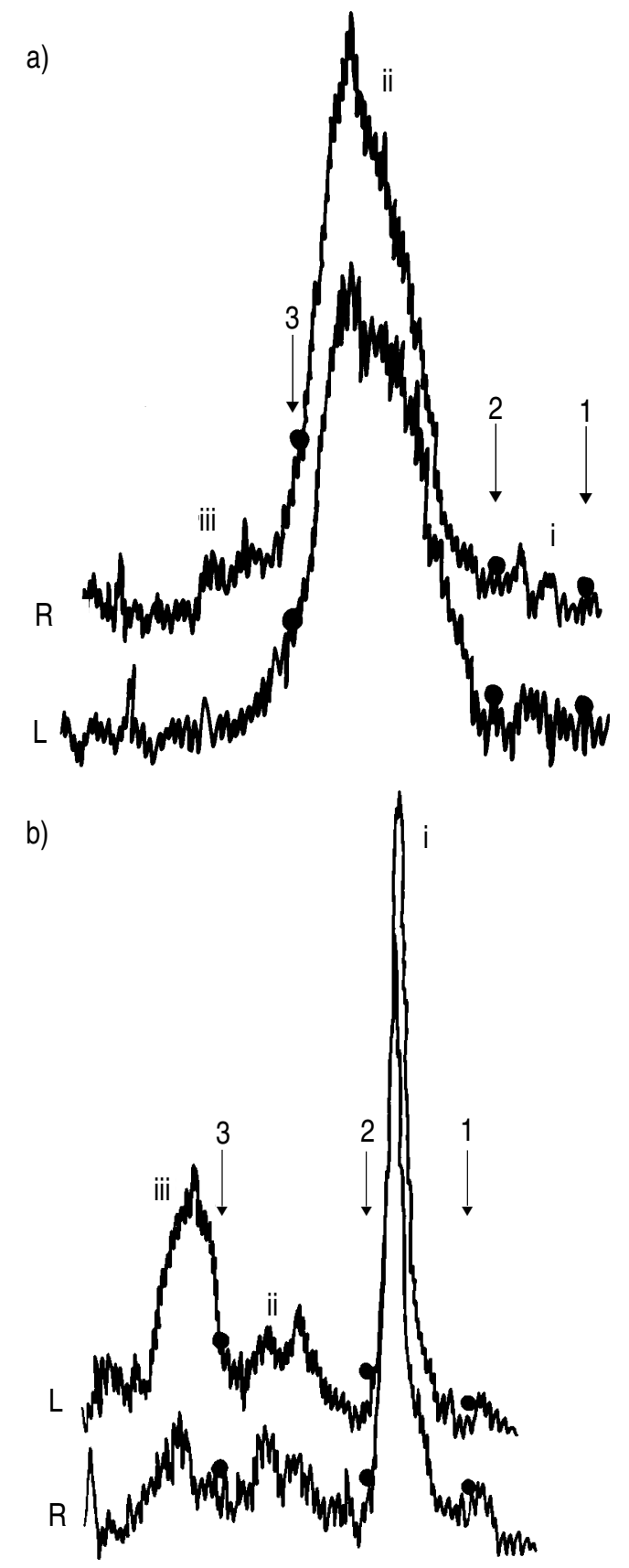

Fig. 2. - Profile scanning curves of two asthmatic subjects: a) with low; and b) with high mouth and throat deposition. External scanning over mouth and throat (i), lungs (ii), and stomach (iii) immediately after inhalation of radiolabelled test particles. The activities measured over the right $(\mathrm{R})$ and left $(\mathrm{L})$ sides of the body are shown. Anatomical landmarks $(\bullet)$ are the tragus of the external ear (1), the cricoid cartilage of the larynx (2), and the xiphoid process (3).

found to be significantly related to increased mouth and throat deposition. These findings agree well with the findings on radioactivity profiles (fig. 2), where the maximum activity is anatomically located over the pharynx, and not over the larynx. Figure 3 shows two photographs, corresponding to these profiles, one with a wide open pharyngeal space (subject No. 15) during inhalation, and the other with a marked constriction at the tongue-base-epiglottic level (subject No. 9). We
Table 3. - Deposition in the mouth and throat, and lung retention at $24 \mathrm{~h}\left(\mathrm{Ret}_{24}\right)$ versus characteristics in pharynx and larynx

\begin{tabular}{lllll}
\hline & $\begin{array}{c}\text { Mouth and throat } \\
\text { deposition } \\
\%(\mathrm{n})^{*}\end{array}$ & \multicolumn{2}{c}{ Ret $_{24}$} \\
& \multicolumn{2}{c}{$\%$ (n) } \\
\hline Pharynx (A) & $17 \pm 8$ & $(10)$ & $64 \pm 9$ & $(9)$ \\
Pharynx (B+C) & $42 \pm 34$ & $(6)^{\#}$ & $58 \pm 17$ & $(6)$ \\
Larynx (A) & $20 \pm 19$ & $(10)$ & $65 \pm 14$ & $(10)$ \\
Larynx (B+C) & $35 \pm 30$ & $(6)$ & $55 \pm 8$ & $(5)$ \\
\hline
\end{tabular}

Values are presented as mean \pm SD. The criteria of catergory $\mathrm{A}, \mathrm{B}$ and $\mathrm{C}$ are given in the Methods section. *: number of subjects; \#: $\mathrm{p}<0.05$, (see further tables 4 and 5).

Table 4. - The Fisher exact test for $2 \times 2$ tables

\begin{tabular}{|c|c|c|c|}
\hline \multicolumn{4}{|c|}{ Mouth and throat deposition } \\
\hline & $70 \%$ & $<70 \%$ & \\
\hline Pharynx (A) & 0 & 10 & 10 \\
\hline \multirow[t]{2}{*}{ Pharynx $(B+C)$} & 3 & 3 & 6 \\
\hline & 3 & 13 & $16(\mathrm{n})^{*}$ \\
\hline
\end{tabular}

*: number of subjects. The criteria of category A, B and C are given in the Methods section.

Table 5. - Pharyngeal evaluation in six asthmatics related to high mouth and throat deposition

\begin{tabular}{ccc}
\hline $\begin{array}{l}\text { Subject } \\
\text { No. }\end{array}$ & $\begin{array}{c}\text { Mouth and throat } \\
\text { deposition } \%\end{array}$ & \multicolumn{1}{c}{$\begin{array}{c}\text { Pharyngeal evaluation } \\
(\mathrm{B}+\mathrm{C})\end{array}$} \\
\hline 1 & 71 & $\begin{array}{l}\text { A marked constriction at the ton- } \\
\text { gue-base-epiglottic level (C). } \\
\text { A moderate narrowing at the } \\
\text { tongue-base-epiglottic level + ton- } \\
\text { sil enlargement (B). } \\
\text { A moderate narrowing at the } \\
\text { tongue-base-epiglottic level (B). } \\
\text { A marked constriction at the } \\
\text { tongue-base-epiglottic level + ton- } \\
\text { sil enlargement (C). } \\
\text { Tonsil enlargement + deviant epig- } \\
\text { lottal shape narrowing the glottal } \\
\text { entrance (B). } \\
\text { A moderate narrowing at the } \\
\text { tongue-base-epiglottic level (B). }\end{array}$ \\
13 & 11 & \\
16 & 71 & \\
\hline $\begin{array}{l}\text { Mean } \\
\text { SD }\end{array}$ & 42 & \\
\hline
\end{tabular}

found a tendency towards higher $\operatorname{Ret}_{24}$ values for patients with A evaluation of the larynx ( $\mathrm{p}=0.075$, Student's one-tailed t-test) (table 3).

The percentage retention of particles in the lungs after $24 \mathrm{~h}\left(\mathrm{Ret}_{24}\right)$ are presented in figure 4 . They were considered to represent the fractions deposited in the alveoli. The $\operatorname{Ret}_{24}$ values were normally distributed with a mean \pm SD of $62 \pm 13 \%$. Among the lung function parameters, $\mathrm{FEF}_{75-85 \%}$ was the only one significantly correlated to 

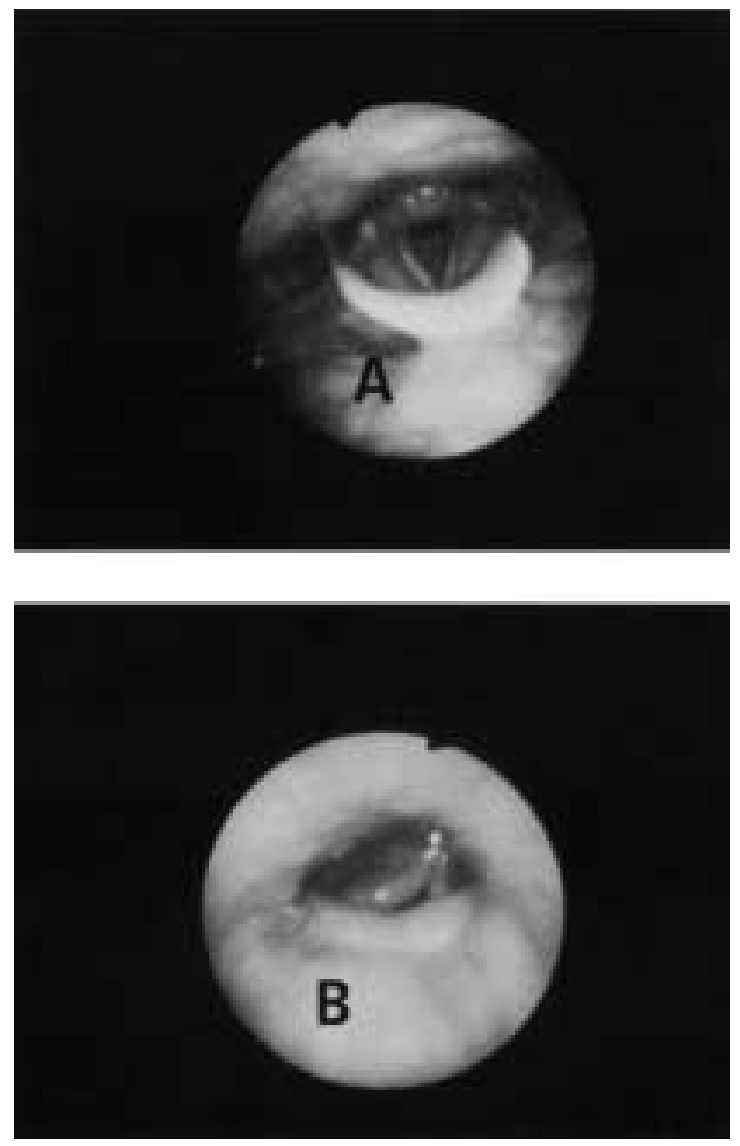

Fig. 3. - Photographs of video recordings of the pharyngeal cavity during inhalation. The same asthmatic subjects are shown as in figure 2: A) with normal opening of the pharyngeal space; and B) with a considerable narrowing.

$\operatorname{Ret}_{24}(\mathrm{p}<0.05 ; \mathrm{r}=0.59)$ (fig. 5). For $\mathrm{N}_{2}$-delta, $\mathrm{r}=-0.50$ $(\mathrm{p}=0.068)$. There was no significant correlation between Raw (range $0.1-1.4 \mathrm{kPa} \cdot \mathrm{s} \cdot l^{-1}$, mean \pm SD $0.3 \pm 0.3$ $\left.\mathrm{kPa} \cdot \mathrm{s} \cdot \mathrm{l}^{-1}\right)$ and $\operatorname{Ret}_{24}(\mathrm{p}>0.05 ; \mathrm{r}=0.29)$. Multiple stepwise regression analysis, including several lung function parameters $\left(\mathrm{Raw}+\mathrm{FEF}_{75-85 \%}+\mathrm{N}_{2}\right.$-delta), did not substantially enhance the correlation.

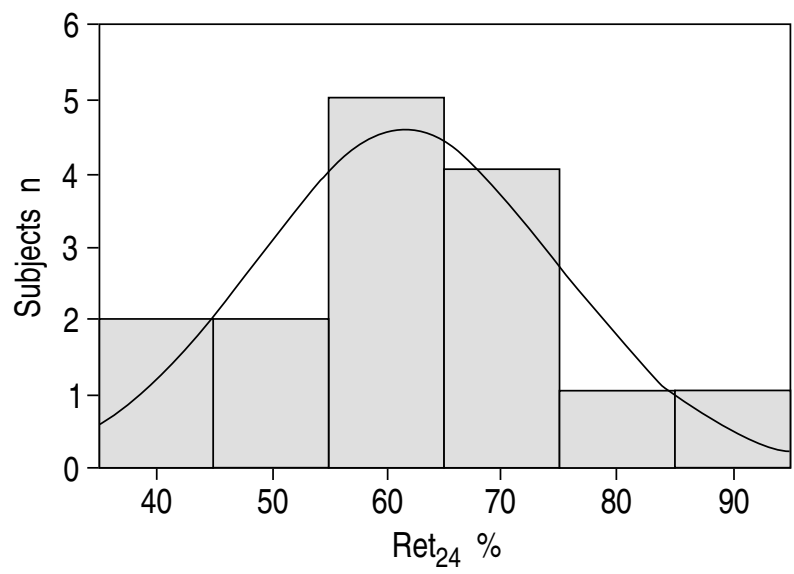

Fig. 4. - Distribution of lung retention of inhaled $3.6 \mu \mathrm{m}$ particles after $24 \mathrm{~h}\left(\operatorname{Ret}_{24}\right)$ in 15 asthmatic subjects. The mean \pm SD was $62 \pm 13 \%$.

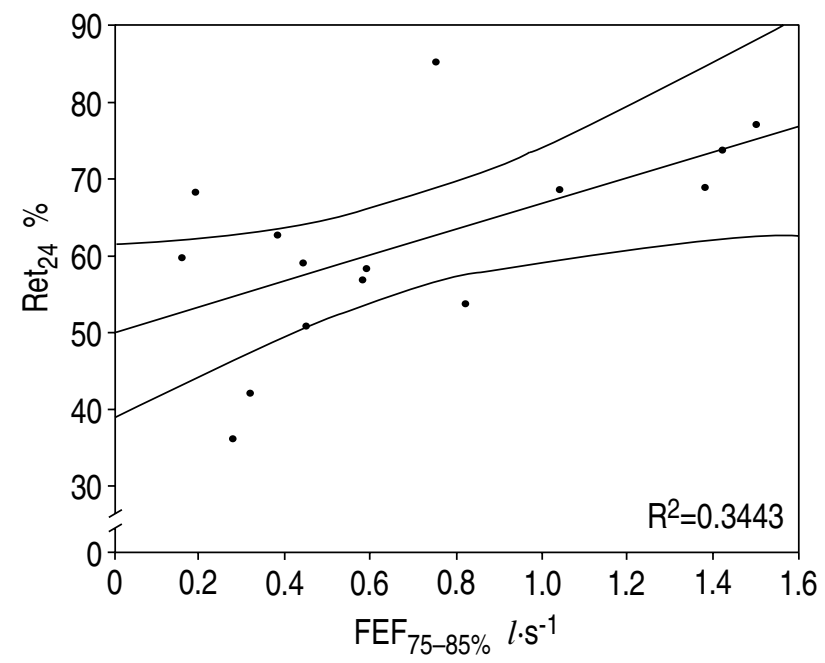

Fig. 5. - Correlation between forced expiratory flow at $75-85 \%$ of forced vital capacity $\left(\mathrm{FEF}_{75-85 \%}\right)$ and the percentage lung retention after $24 \mathrm{~h}\left(\operatorname{Ret}_{24}\right)$ in 15 asthmatics. Regression line with mean and 95\% confidence interval is shown.

\section{Discussion}

Deposition of inhaled particles in mouth and throat is highly variable in healthy subjects and in patients with asthma. Mouth and throat deposition was found to be $27 \pm 14 \%$ (mean \pm SD) in healthy subjects at a similar flow rate and particle size to that used in the present study [9]. Increasing inhalation flow rate from 0.4 to $1.2 l \cdot \mathrm{s}^{-1}$ increased particle deposition from $20 \pm 12$ to $38 \pm 19 \%$ [2]. In a recent study in patients with asthma, a quarter of the subjects were found to have high mouth and throat deposition ( $>30 \%$ ) during repeated measurements [4]. Among the 16 patients in the present study, we found three subjects with high mouth and throat deposition, which agreed well with these previous results.

In the present study, we found functional differences both in the pharynx and larynx. Among them, deviations in the pharynx were found to be significantly related to high mouth and throat deposition, whereas dysfunction in the larynx was not. These findings agreed well with the radioactivity profiles, where the maximum mouth and throat activity was anatomically located above the larynx. We have no reason to believe that the shape or function of pharynx and larynx would be influenced by the laryngoscopic examination itself.

A marked functional constriction at the tongue-baseepiglottic level, thus, seems to be one reason for high mouth and throat deposition. This finding indicates that training programmes might be valuable for patients treated with therapeutic aerosols. One explanation for this narrowing might be that it was produced by the subjects in order to maintain a fairly constant flow rate throughout the inhalation. In our inhalation system, the particles are inhaled practically without resistance. Increased flow resistance might alter the conditions of mouth and throat deposition, an issue we intend to investigate further.

Particle deposition in the pharynx is probably due to 
turbulence. Since one of the patients (No. 13) with high deposition had a deviant shape of the epiglottis rather than a very narrow pharynx, and another patient (No. 7) with rather high deposition $(34 \%)$ had a normal pharyngeal width, one may speculate that both the shape and the width of the tube are important factors. No absolute measurements of the pharyngeal width could be made with the method used. However, the fact that three patients with low deposition still showed a certain degree of pharyngeal narrowing suggests that a critical width might exist at which deposition starts to occur. Other factors, such as the shape of the oral cavity, tongue position during inhalation, and the condition of the mucosa, may be of importance.

Regarding adverse effects of inhaled steroids, no obvious relation to high mouth and throat deposition was found. There were subjects with frequently occurring adverse effects who showed low deposition and subjects without side-effects who showed extremely high deposition. Apparently, there might be factors other than local dose which might be more important for the development of side-effects, as for instance individual susceptibility to steroids, and total dose daily administered. The present study, however, was not aimed at answering these specific questions.

We found a significant correlation between Ret $_{24}$ and $\mathrm{FEF}_{75-85 \%}$ (reflecting smaller airways), and a somewhat weaker correlation between $\operatorname{Ret}_{24}$ and $\mathrm{N}_{2}$-delta, which agreed with previous findings in asthmatics [10]. In contrast with previous findings $[10,11]$, we found no significant correlation between $\operatorname{Ret}_{24}$ and Raw (reflecting larger airways). This is probably due to the fact that the Raw values in the present group of asthmatics were low and within a narrow range.

In conclusion, this study confirms that among asthmatics there are subpopulations with an extremely high mouth and throat deposition. It also indicates that changes in pharyngeal configuration, functional and/or anatomical, may cause high deposition of particles in mouth and throat. Further studies are needed to investigate the precise location of deposition in the oropharynx, and thus different possibilities to reduce mouth and throat deposition.
Acknowledgements: The authors thank K. Örnefalk, K. Widtskiöld-Olsson, B. Nilsson and U. Bergsten for expert technical assistance.

\section{References}

1. Lippmann M, Albert RE, Peterson HT. The regional deposition of inhaled aerosols in man. In: Walton WH, ed. Inhaled Particles. III. Surrey, Unwin Bros Ltd, 1971; pp. 105-120.

2. Anderson M, Svartengren M, Philipson K, Camner P. Deposition in man of particles inhaled in air or heliumoxygen mixture at different flow rates. J Aerosol Med 1990; 3: 209-216.

3. Stahlhofen W, Rudolf G, James AC. Intercomparison of experimental regional aerosol deposition data. $J$ Aerosol Sci 1989; 2: 285-308.

4. Svartengren M, Anderson M, Bylin G, Philipson K, Camner P. Mouth and throat deposition of $3.6 \mu \mathrm{m}$ radiolabelled particles in asthmatics. J Aerosol Sci 1991; 4: 313-321.

5. Quanjer PH, (Ed.). Standardized lung function testing. Report Working Party "Standardization of Lung Function Tests". European Community for Coal and Steel. Bull Eur Physiopathol Respir 1983; 19(5): 7-10.

6. Camner P. The production and use of test aerosols for studies of human tracheobronchial clearance. Environ Physiol Biochem 1971; 1: 137-154.

7. Philipson K. Monodisperse labelled aerosols for studies of lung clearance. In: Abstracts of Uppsala. Dissertations from the Faculty of Science, Uppsala, Sweden. 1977; 433: 1-36.

8. Svartengren M, Falk R, Linnman L, Philipson K, Camner P. Deposition of large particles in human lung. Exp Lung Res 1987; 12: 75-88.

9. Svartengren M, Anderson M, Philipson K, Camner P. Human lung deposition of particles suspended in air or in helium/oxygen mixture. Exp Lung Res 1989; 15: 575-585.

10. Svartengren M, Anderson M, Bylin G, Philipson K, Camner P. Regional deposition of $3.6 \mu \mathrm{m}$ particles and lung function in asthmatic subjects. J Appl Physiol 1991; 71(6): 2238-2243.

11. Svartengren M, Anderson M, Bylin G, Philipson K, Camner P. Regional deposition of $3.6 \mu \mathrm{m}$ particles in subjects with mild to moderately severe asthma. J Aerosol Med 1990; 3: 197-207. 